\title{
ТЕХНОЛОГІЧНЕ УСПАДКОВУВАННЯ ВЛАСТИВОСТЕЙ ПРИ ЗАБЕЗПЕЧЕННІ ПАРАМЕТРІВ ЯКОСТІ ВИРОБУ В ПРОЦЕСІ ЙОГО ВИГОТОВЛЕННЯ
}

Анотація. Відзначено безпосередній зв'язок параметрів якості виробів із етапами та стадіями його життєвого циклу. На основі аналізу літературних джерел визначено забезпечення експлуатаційних характеристик виробів із дотриманням вимог конструкторсько-технологічної документації одним із пріоритетних завдань сучасної технології машинобудування. Проаналізовано недопустимі відмови виробів, що пов'язані із технологією їх виготовлення. Розроблено принципову схему формування параметрів якості деталей машин та запропоновано вираз для прогнозування імовірності невідбракування $P(t)$ придатних до подальшої експлуатації виробів із врахуванням технологічного успадковування. Розглянуто особливості оцінки пошкоджуваності заготовок виробів для обробки тиском і литва.

Ключові слова: якість, життєвий цикл виробу, експлуатаційні характеристики, технологічний процес, технологічне середовище, технологічне успадковування, пошкоджуваність, заготовка

Постановка проблеми. Одним із пріоритетних завдань сучасного машинобудівного виробництва $\epsilon$, поряд із підвищенням якості машин загалом і деталей зокрема, забезпечення їх експлуатаційних характеристик та параметрів надійності. Розв'язання цієї проблеми досягається шляхом керування технологічними процесами механічного оброблення деталей і складання машин при виконанні технічних вимог конструкторсько-технологічної документації, зокрема забезпеченні точності геометричних розмірів, досягненні параметрів якості поверхні та бажаних фізико-механічних властивостей, макровідхилень форми й взаємного розташування виконавчих поверхонь [1,2].

Параметри якості виробу: точність оброблення, параметри якості поверхні, експлуатаційні характеристики та показники надійності тісно

(c) Кусий Я.М., 2019 
«Системні технологіï» 5 (124) 2019 «System technologies»

пов’язані з етапами та стадіями його життєвого циклу [3]. Формування та перетворення властивостей виробів забезпечується протягом технологічного маршруту їх виготовлення: від заготівельних до фінішних і викінчувально-зміцнювальних операцій. Сумарна похибка формується із елементарних складових, починаючи від отримання заготовки, механічного оброблення різанням, складання, випробування, контролю та запуску у виробництво. Це дозволяє стверджувати про технологічне успадковування властивостей деталей i машин через трансформацію показники їх якості від попередніх до наступних технологічних операцій. Ефект успадковування підсилюється із підвищенням вимог до точності виробів [1, 2].

Однак в сучасній літературі при аналізі впливу технологічного успадковування на параметри якості виробу/машини недостатньо враховується роль заготівельних операцій. Структуру та властивості заготовок потрібно аналізувати в тісному поєднанні із спадковістю металу 3 рідкого стану. Проте 75 \% формується під час заливання та затверднення при охолоджуванні. Лише 25 \% властивостей шихти передається заготовці [4].

Формування та перетворення властивостей поверхневого шару в рамках механіки технологічного успадковування вимагає грунтовних теоретико-експериментальних досліджень для розроблення передумов для широкого впровадження PLM-концепцій у практику машинобудівного виробництва.

Розроблення алгоритму формування параметрів якості виробу під час його виготовлення із математичним описом технологічного успадковування властивостей дозволить започаткувати роботи стосовно розроблення раціональних технологічних процесів в умовах автоматизованого виробництва.

Аналіз останніх досліджень і публікацій. В традиційних (класичних) автоматизованих системах технологічної підготовки машинобудівного виробництва здійснюється покрокове виконання взаємопов’язаних етапів проектування маршруту виготовлення деталі. На підставі отриманих від конструктора відправних даних: складальне крес- 
«Системні технології» 5 (124) 2019 «System technologies»

лення машини та робочі креслення деталей із нормативнообгрунтованими відповідно до експлуатаційних умов параметрами точності та якості поверхонь, технічними вимогами, матеріалом тощо проектується структура технологічного маршруту механічного оброблення виробу, яка може коректуватися та узгоджуватися відповідно до функціональних можливостей наявного технологічного середовища (системи верстат-пристрій-інструмент-заготовка) та (за потреби) розроблюється керуюча програма для верстатів з чПК. У цьому випадку критерієм оптимізації при виборі раціонального варіанту технологічного процесу служить, як правило, мінімальна технологічна собівартість виготовлення виробу при максимальній продуктивності основного технологічного обладнання без функціонального аналізу експлуатаційних характеристик виробу, покладаючись на кваліфікацію та технічну грамотність конструктора. Такий технологічний процес називають об’єктно-орієнтованим.

Пріоритетним завданням сучасних технологій машинобудівного виробництва має бути забезпечення заданих експлуатаційних характеристик виробів із дотриманням призначених конструктором параметрів точності та якості поверхневих шарів їх виконавчих поверхонь на відміну від досягнення мінімальної технологічної собівартості при максимальній продуктивності праці для класичної технології машинобудування. Виробничий досвід машинобудівних підприємств свідчить, що залежності експлуатаційних властивостей і показників якості готового виробу складні. Конструктор (або автоматизована CAD/CAE система), виходячи iз службового призначення машини/виробу, розробляє конструкцію визначеного виробу, обмежуючись спрощеним аналізом напруженодеформованого стану деталі, та призначає техніко-економічно обгрунтовані норми точності та параметри якості, а також взаємного розташування виконавчих поверхонь без детального аналізу реальних експлуатаційних умов із залученням грунтовно розроблених математичних моделей.

Сучасний розвиток прикладної механіки, свідчить, що технологічне забезпечення основних експлуатаційних характеристик виробу (тримка здатність, зносостійкість, втомна міцність, міцність 
«Системні технологіï» 5 (124) 2019 «System technologies»

з’єднання тощо) вимагають системного підходу, що полягає не лише у дослідженні реальних фізичних процесів на усіх рівнях: субмікроскопічному, мікроскопічному та макроскопічному, а й їх покроковому відслідковуванні на усіх стадіях та етапах життєвого циклу виробу з позиції технологічного успадковування. Технологічним успадковуванням називають процес перенесення властивостей об'єкту від попередніх технологічних операцій до наступних. Збереження цих властивостей у об’єкті називають технологічною спадковістю. Згідно з цим підходом системний принцип реалізації життєвого циклу машинобудівного виробу 3 позиції технологічного успадковування вимагає прямого зв’язку технологічної підготовки виробництва із стадією експлуатацією iз не покроковою, а паралельною, узгодженою роботою конструктора та технолога.

Тому для системного забезпечення життєвого циклу виробу є актуальним розроблення наукових і прикладних засад технологічного успадковування параметрів якості для забезпечення експлуатаційних характеристик виробів при проектуванні функціонально-орієнтованих технологій. Під функціонально-орієнтованим технологічним процесом (ФОТП) розуміють такий ТП, який спрямований на забезпечення найефективніших експлуатаційних характеристик виробу із дотриманням призначених конструктором параметрів точності та якості поверхневого шару виробу. Вирішення цього завдання можливе за рахунок автоматизованого керування процесами та ретельного аналізу усього технологічного ланцюга виготовлення деталей з позиції технологічного успадковування, за рахунок системно інтегрованих CAD/CAE/CAPP/CAM програмних продуктів. При впровадженні ФОТП інтенсифікуються роботи конструкторсько-технологічної підготовки виробництва на забезпечення максимального позитивного результату у ланцюгу замовник-виробник.

Мета дослідження. Метою даного дослідження $\epsilon$ розроблення принципової схеми формування параметрів якості виробу із прогнозуванням ймовірності його невідбракування під час виготовлення із врахуванням технологічного успадковування властивостей. 
«Системні технології» 5 (124) 2019 «System technologies»

Викладення основного матеріалу дослідження. Роль технології у формуванні параметрів якості виробів є визначальною. Встановлено, що при правильно призначених режимах обробки суттєво підвищується довговічність деталей, в той час як невірно призначені режими і неврахування накопичення дефектів на попередніх операціях, зокрема і на заготівельних, можуть привести до руйнування поверхневого шару вже на етапі виготовлення або до передчасного руйнування деталі на стадіях експлуатації [2].

Тому структура технологічного процесу має безпосередній i істотний вплив на формування параметрів якості виробу. Технологічні режими фінішних і викінчувально-зміцнювальних операцій відіграють важливу роль у формуванні не лише параметрів якості, а й експлуатаційних характеристик та показників надійності, хоча зв'язки між ними складні, багатоетапні і не є очевидними (рис. 1).

\begin{tabular}{|c|c|c|c|}
\hline $\begin{array}{l}\text { Технологічн } \\
\text { (послідовніст } \\
\text { режими обр } \\
\text { методи конт }\end{array}$ & $\begin{array}{r}\text { Пара } \\
\text { вигото } \\
\text { (точн } \\
\text { якіст }\end{array}$ & $\begin{array}{l}\text { ні } \\
\text { оббу } \\
\mathrm{b}, \mathrm{s}\end{array}$ & ресурс \\
\hline
\end{tabular}

Рисунок 1 - Схема залежності параметрів ТП із параметрами якості виготовлення виробу, його експлуатаційними характеристиками та показниками надійності

Оскільки технологічні процеси виготовлення виробів забезпечують параметри якості та експлуатаційні характеристики деталей машин, то вони безпосередньо пов'язані із формуванням і виникненням відмов. Найбільшу увагу слід приділяти недопустимим відмовам, коли їх характер відмови або швидкість їх протікання не відповідає встановленим технічним умовам. Відмови такого плану є результатом недосконалості технологічного процесу. Класифікація причин, що призводять до недопустимих відмов через технологію, приведена на рис. 2 [5].

Недопустимі відмови, пов'язані з технологією, відносять до III груп (рис.2). Перша група причин пов'язана 3 необгрунтованістю технічних умов на параметри вироби і на допуски його елементів, 3 недосконалістю прийнятої технологічної документації, 3 недоліками методів випробування на надійність готового виробу і його механізмів ISSN 1562-9945 
«Системні технології» 5 (124) 2019 «System technologies»

(рис. 2). Необгрунтованість технічних умов на виріб (I група) перш за все пов’язана із неякісною роботою конструктора на етапі конструкторської підготовки виробництва. Основні технічні умови на виріб повинні забезпечувати як параметри якості, так і експлуатаційні характеристики виробу. Відмови, пов’язані з цією групою, зазвичай не відображають всіх основних вимог до виробу, які і визначають його експлуатаційні характеристики та параметри надійності, не враховують властивості, отримані виробом в процесі його виготовлення [5].

\begin{tabular}{|c|c|c|}
\hline & Відмови, пов'язані з техноло & \\
\hline $\begin{array}{l}\text { Необгрунтованість } \\
\text { технічних умов (ТУ) }\end{array}$ & \begin{tabular}{c|} 
Недостатня надійність \\
технологічного середовища
\end{tabular} & $\begin{array}{c}\text { Залишкові та побічні } \\
\text { явища }\end{array}$ \\
\hline$=$ ТУ на параметри виробу & $\begin{array}{c}\text { Запас надійності } \\
\text { технологічного середовища }\end{array}$ & \begin{tabular}{|c|} 
Виникнення \\
технологічних дефектів
\end{tabular} \\
\hline \begin{tabular}{|c|} 
ТУ на параметри \\
технологічного процесу
\end{tabular} & $\begin{array}{c}\text { Ефективність } \\
\text { контрольних операцій }\end{array}$ & $\begin{array}{c}\text { Наступна зміна } \\
\text { властивостей }\end{array}$ \\
\hline ТУ на випробування & $\begin{array}{c}\text { Tехнологічна надійність } \\
\text { обладнання }\end{array}$ & Технологічна спадковість \\
\hline
\end{tabular}

Рисунок 2 - Класифікація недопустимих відмов, пов’язаних 3 недосконалістю технологічних процесів

Зв’язки між параметрами технологічного процесу i експлуатаційними властивостями виробів зазвичай складні i мало досліджені для змінних експлуатаційних умов [1,2].

Технічні умови на вироби, як правило, не регламентують увесь комплекс основних параметрів інженерії поверхні, а часто обмежуються вказанням шорсткості поверхні та її мікротвердості. Крім того, не завжди враховуються структура операцій, режими різання матеріалів, прогресивні методи обробки, які вибирають загалом з умови забезпечення високої продуктивності. Як наслідок, при різних технологічних процесах виготовлення виробів отримують деталі із різними експлуатаційними характеристиками та ступенем надійності, що можна прослідкувати на прикладі прецизійних шпинделів, турбінних лопаток, складних корпусів тощо [1,2].

Із підвищенням вимог до експлуатаційних характеристик виробів, необхідно збільшувати число параметрів у технічних умовах і визначати 
«Системні технологіï» 5 (124) 2019 «System technologies»

основні взаємозв'язки між експлуатаційними характеристиками i технологічними параметрами виробів. Складність розроблення засобів і методів випробування деталей і машин на надійність привела до формування самостійної галузі в проблемі забезпечення експлуатаційних характеристик і надійності виробів [5].

Друга група причин, що призводить до неприпустимих відмов 3 вини технології, пов'язана 3 недостатньою надійністю технологічного середовища (рис. 2).

Функціонування технологічної системи потрібно розглядати як взаємодію її досліджуваного (визначеного) складника із середовищем, яке формується технологічними об’єктами будь-якої технологічної системи [1].

Отже, технологічне середовище - це сукупність технологічних об'єктів, які взаємодіють 3 визначеним (досліджуваним) технологічним об’єктом на певному етапі виготовлення деталей i/aбо складання машини $[1,2]$.

Технологічне середовище є складною динамічною системою 3 великою кількістю взаємозв'язків, яка характеризується багатьма кінцевими (вихідними) параметрами.

Третя група причин виникнення неприпустимих відмов пов'язана з залишковими і побічними явищами, що формуються в ході виконання технологічного процесу (рис. 2). Раціональні технологічні процеси виготовлення виробів від заготівельних до фінішних операцій характеризуються, зазвичай, значними силовими і температурними впливами на деталь при надвисоких вимогах до точності оброблення, високої якості поверхневого шару і продуктивності процесу [1].

Власне третя група причин виникнення неприпустимих відмов, зокрема і вплив технологічного успадковування, вимагають подальшого дослідження для встановлення їх впливу на формування параметрів якості виробу під час реалізації технологічного процесу його виготовлення.

Розглянемо принципову схему формування параметрів якості виробу в ході виконання технологічного процесу, що складається 3 
послідовних операцій - від заготівельної (0) до кінцевої (n) (рис. 3) [4]. Множина значень $\mathrm{Y}_{01}, \mathrm{Y}_{02}, \ldots . . \mathrm{Y}_{0 \mathrm{j}}$ служить відправними, а сукупність характеристик $\mathrm{X}_{1}, \mathrm{X}_{2}, \ldots . .$. ., $\mathrm{X}_{\mathrm{m}}$ - вихідними параметрами реалізації технологічного процесу виготовлення.

При аналізі забезпечення вихідних параметрів технологічного процесу зручно користуватися показниками безвідмовності, зокрема $\mathrm{P}_{\mathrm{i}}(\mathrm{t})$ - імовірністю невідбракування придатних до подальшої експлуатації виробів на $i$-тій операції технологічного процесу, що визнчається впливом технологічного середовища (рис. 3). Імовірність $\mathrm{P}_{0}(\mathrm{t})$ характеризує невідбракування придатних до подальшої експлуатації виробів на заготівельній технологічній операції, а $\mathrm{P}_{1}(\mathrm{t})$ - на першій операції ТП тощо.

Імовірність $\mathrm{P}(\mathrm{t})$ - імовірність неперевищення будь-яким 3 технологічних параметрів границь допуску протягом заданого періоду часу $\mathrm{t}=\mathrm{T}$ визначає імовірність невідбракування придатної до подальшої експлуатації виготовленої деталі. Формування вихідних параметрів відбувається в результаті послідовного оброблення заготовки, що забезпечується принципами технологічного успадковування. Для кожної операції, як правило, призначені свої нормативні показники, які мають бути забезпечені в результаті виконання технологічних переходів даної технологічної операції.

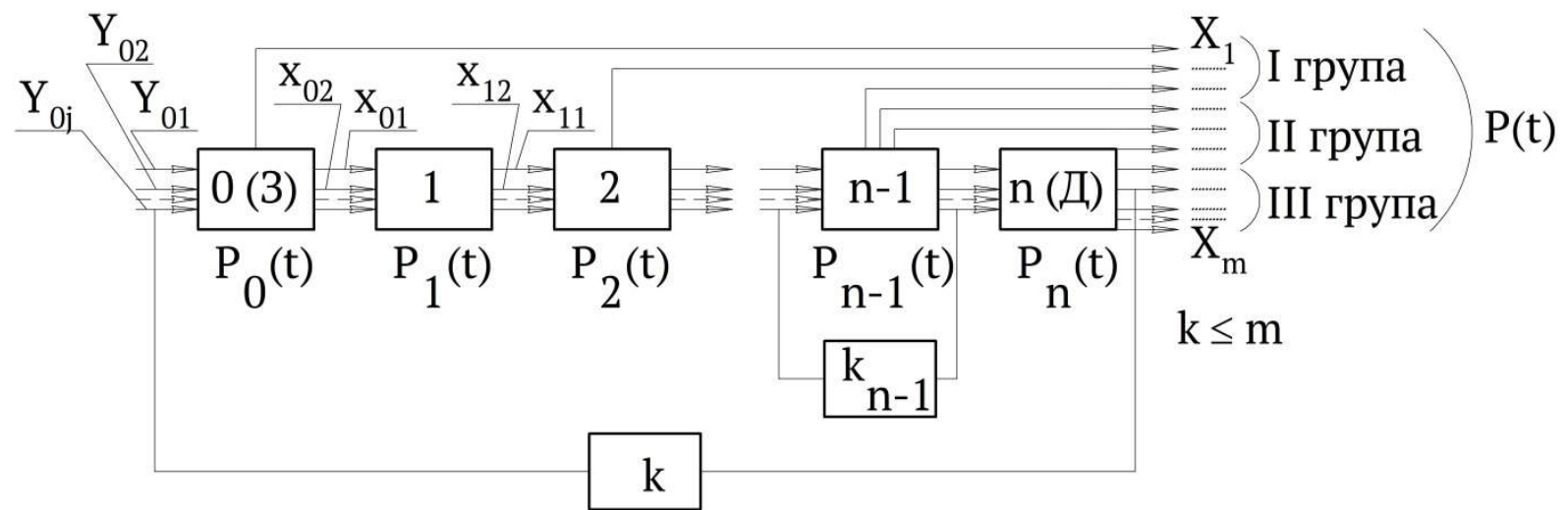

Рисунок 3 - Принципова схема формування параметрів якості виробу під час реалізації технологічного процесу його виготовлення Отримуємо III групи вихідних параметрів виробу [4].

1. Частина параметрів виробу, контрольованих на проміжних операціях, зазнає змін і їх значення суттєво не впливають на кінцеві по- 
казники виробу (параметри I групи, рис. 3). Однак характеристики матеріалу, які є відправними параметрами технологічного процесу, у значній мірі визначають і його кінцеві властивості.

2. Переважна більшість параметрів фінішних і викінчувальнозміцнювальних технологічних операцій безпосередньо впливають на формування параметрів якості виробів. Саме ймовірність їх забезпечення в межах допуску суттєво впливає на ймовірність невідбракування кінцевої деталі (параметри II групи, рис. 3).

3. Деякі параметри фінішних та викінчувально-зміцнювальних операцій, формування яких підпорядковується принципам технологічного успадковування. Тому частина кінцевих (вихідних) параметрів (III група, рис. 3) функціонально пов’язана з параметрами попередніх проміжних операцій.

Розглянемо кінцевий результат отримання $m$ вихідних параметрів деякого технологічного ланцюга (рис. 3). Вважаємо, що для кожного 3 технологічних параметрів визначена ймовірність $\mathrm{P}_{\mathrm{xi}}$ Його отримання в межах допуску I-III груп із можливістю проміжного контролю для частини 3 них. Ефективність вихідного контролю характеризується ймовірністю $\mathrm{P}_{\mathrm{k}}$ відбракування виробів, якщо параметри перевищують межі допуску. Для неконтрольованих параметрів $\mathrm{P}_{\mathrm{k}}=0$, для абсолютно надійного контролю $\mathrm{P}_{\mathrm{k}}=1$.

У роботі [4] отримана формула для оцінки ймовірності невідбракування виробів $\mathrm{P}(\mathrm{t})$ при m вихідних (кінцевих) параметрах для заданого технологічного процесу:

$$
P(t)=\prod_{i=1}^{m}\left[1-\left(1-P_{0}(t)\right)\left(1-P_{x_{i}}(t)\right) \cdot\left(1-P_{k}(t)\right)\right] \text {. }
$$

При структурному аналізі та синтезі варіантів технологічного процесу механічного виготовлення виробу розглядають як альтернативні варіанти структури механічного оброблення деталі, так і методи отримання раціональної заготовки як з позиції дотримання технічних вимог конструкторсько-технологічної документації, так i забезпечення необхідних експлуатаційних характеристик виробу. 
«Системні технології» 5 (124) 2019 «System technologies»

В зв’язку 3 цим необхідно враховувати незалежний вплив ймовірності невідбракування виробів $\mathrm{P}_{0}(\mathrm{t})$ на заготівельній технологічній операції у структурі ймовірності невідбракування виробів $\mathrm{P}(\mathrm{t})$ при реалізації технологічного процесу.

$$
P(t)=\left[1-\left(1-P_{0}(t)\right)\right] \cdot \prod_{i=1}^{m}\left[1-\left(1-P_{x_{i}}(t)\right) \cdot\left(1-P_{k}(t)\right)\right] \text {. }
$$

$P_{0}(t), P_{x i}(t), P_{k}(t)$ представляють прогнозування властивостей виробу в процесі його виготовлення і можуть бути визначені лише при покроковому дослідженні структури ТП з позиції технологічного успадковування.

При дослідженні фізичних процесів при виготовленні виробів на субмікроскопічному рівні для визначення складових формули (2) потрібно враховувати закон сумування пошкоджуваності протягом життєвого циклу виробу [6,7]:

$$
D=\sum D_{j}
$$

де D (damageability) - сумарна пошкоджуваність виробу; $\mathrm{D}_{\mathrm{j}}$ пошкоджуваність для ј-ого часового інтервалу життєвого циклу виробу.

Особливості формування пошкоджуваності матеріалу виробу на субмікроскопічному рівні досліджень, що визначає технологічну спадковість його властивостей, визначаються методом отримання заготовки. Розглянемо два основних методи отримання заготовок у машинобудуванні: обробка тиском та литво.

1. Заготовки, отримані обробкою тиском.

Моделі механіки пошкодження при формоутворенні заготовок обробкою тиском (кування, штамповка тощо) класифікуються на дві категорії: зв’язані (що враховують взаємодію стосовно накопичення пошкоджень на субмікроскопічному рівні) та незв’язані (що не враховують взаємодію) моделі. Зв’язані моделі враховують ефект накопичення пошкоджень в рівняннях стану [6,7].

На відміну від зв’язаних, незв’язані моделі визначають критичний стан навантаження, що відповідає за появу руйнування, обумовленого тривісністю напружень та кутом Лоде. Умови навантаження зазвичай характеризуються функцією ваги еквівалентної пластичної деформації, i 
відповідна критична еквівалентна пластична деформація до руйнування виражається як $\bar{\varepsilon}_{f}[6,7]$.

У роботі [6] для позначення моменту, коли пошкодження починають відігравати роль у процесі, вводиться емпірична модель пошкодження, причому чітко розмежовані два стани: виникнення руйнування та зародження тріщин. Руйнування описує макроскопічну характеристику, яка може бути визначена як така, що виникає, коли компонент або система перестає виконувати свої вимоги до обслуговування. Зародження тріщин (визначається деформацією зародження тріщини $\bar{\varepsilon}_{i}$ ) описує мікроскопічну характеристику (режим), які можна визначити як такі, що виникають, коли мікроструктура розвиває незворотню деградацію для відправного лінійного масштабу (відправної довжини).

Згідно [6], для в’язкопластичного руйнування залежно від умов навантаження розраховують пошкоджуваність $D$ :

$$
D= \begin{cases}0 ; & \bar{\varepsilon} \leq \bar{\varepsilon}_{i}, \\ \int_{\bar{\varepsilon}} \frac{\sigma_{y 0} \cdot L}{2 \cdot G_{f}} \cdot d \bar{\varepsilon} ; & \bar{\varepsilon}_{i}<\bar{\varepsilon}<\bar{\varepsilon}_{f}, \\ D_{c r} ; & \bar{\varepsilon}=\bar{\varepsilon}_{f} .\end{cases}
$$

де $\sigma_{y 0}$ - значення напруження текучості під час пошкодження; $L$ - характерна довжина для зменшення залежності сітки в моделі кінцевих елементів; $G_{f}$ - енергія, необхідна для відкриття питомої площі тріщини; $D_{c r}$ - критичне значення пошкоджуваності.

2. Заготовки, отримані литвом.

Для математичного опису процесів формоутворення заготовки при литві використано експериментально-розрахунковий метод для прогнозування пошкоджуваності матеріалу. У Національному університеті «Львівська політехніка» адаптовано метод LM-твердості для аналізу та оцінки перетворення неоднорідностей приповерхневих шарів заготовок, отриманих в умовах лиття, в технологічні дефекти та пошкодження при обробці різанням. В якості параметра пошкоджуваності прийнято не абсолютне значення фізичної величини, а ступінь розсіювання показників фізико-механічних властивостей матеріалу, отриманих під час експериментальних досліджень при різних інтервалах навантажень $[3,4]$.

Як параметр розсіювання використано коефіцієнт гомогенності 
«Системні технологіï» 5 (124) 2019 «System technologies»

Вейбулла m [4]:

$$
m=\frac{d(n)}{2,30259 \cdot S(\lg (H))},
$$

де d(n) - параметр, що залежить від кількості вимірювань n

$$
\begin{aligned}
& S(\lg (H))=\sqrt{\frac{1}{n-1} \cdot \sum_{i=1}^{n}\left(\lg \left(H_{i}\right)-\overline{\lg (H)}\right)^{2}}, \\
& \overline{\lg (H)}=\frac{1}{n} \cdot \sum_{i=1}^{n} \lg \left(H_{i}\right) .
\end{aligned}
$$

Технологічну пошкоджуваність D обчислюють за формулою [4]:

$$
D=\frac{m_{\max }-m_{i}}{m_{\max }},
$$

де $\mathrm{m}_{\mathrm{i}}$ - значення коефіцієнта Вейбулла для $i$-ого перерізу серії вимірювань; $m_{\max }$ - максимальне значення коефіцієнта Вейбулла для серії вимірювань.

Висновки. Розроблено структурну схему формування параметрів якості виробу під час реалізації технологічного процесу його виготовлення. Запропоновано математичну залежність для прогнозування імовірності невідбракування придатних до подальшої експлуатації машинобудівних виробів $\mathrm{P}(\mathrm{t})$ із врахуванням структури технологічного процесу та технологічного успадковування властивостей. Подальші дослідження у цьому напрямку пов'язані 3 оптимізацією структури технологічних процесів із врахуванням технологічної спадковості при раціональному поєднанні заготівельних, проміжних, фінішних і викінчувально-зміцнювальних операцій.

\section{ЛІТЕРАТУРА / ЛИТЕРАТУРА}

1. Васильев А. С. Технологические основы управления качеством машин / А. С. Васильев, А. М. Дальский, С. А. Клименко и др. - М.: Машиностроение, 2003. - 256 с.

2. Ящерицын П. И. Технологическая наследственность в машиностроении / П. И. Ящерицын, Э. В. Рыжов, В. И. Аверченко. - Минск: Наука и техника, 1977. - 256 с.

3. Kusyi Ya.M. Investigation of the technological damageability of castings at the stage of design and technological preparation of the machine Life Cycle / Ya.M. Kusyi, , A.M. Kuk // Journal of Physics: Conference Series. - Volume 1426. - - 2020. https://iopscience.iop.org/article/10.1088/17426596/1426/1/012034/pdf. doi:10.1088/1742-6596/1426/1/012034

4. Кузін О. А. Вплив технологічної спадковості на параметри надійності 
виробів / О. А. Кузін, Я. М. Кусий, В. Г. Топільницький // Технологический аудит и резервы производства. - Т. 1, № 1 (21). - 2015. - С. 15-21. doi: 10.15587/2312-8372.2015.37678.

5. Проников А. С. Надежность машин / А. С. Проников. - М. : Машиностроение, 1978. - 592 с.

6. Xue L. Constitutive modeling of void shearing effect in ductile fracture of porous materials / L. Xue // Engineering Fracture Mechanics. - Volume 75 (11). - 2008. - P. 3343-3366.

7. Lian J. A hybrid approach for modelling of plasticity and failure behaviour of advanced high-strength steel sheets / J. Lian, M. Sharaf, F. Archie., S Mu“nstermann // International Journal of Damage Mechanics. Volume 22 (2). - 2008. - P. 188-218.

\section{REFERENCES}

1. Vasil'ev A. S. Tehnologicheskie osnovy upravleniia kachestvom mashin / A.

S. Vasil'ev, A. M. Dal'skii, S. A. Klimenko et al. - M.: Mashinostroenie, 2003. $256 \mathrm{p}$.

2. Yashcheritsyn P. I. Tehnologicheskaia nasledstvennost' v mashinostroenii / P. I. Yashcheritsyn, E. V. Ryzhov, V.I. Averchenko. - Minsk: Nauka i tehnika, 1977. - $256 \mathrm{p}$.

3. Kusyi Ya.M. Investigation of the technological damageability of castings at the stage of design and technological preparation of the machine Life Cycle / Ya.M. Kusyi, A.M. Kuk // Journal of Physics: Conference Series. - Volume 1426. - 2020.

https://iopscience.iop.org/article/10.1088/1742-6596/1426/1/012034/pdf. doi:10.1088/1742-6596/1426/1/012034

4. Kuzin O. A. Vplyv tekhnolohichnoi spadkovosti na parametry nadiinosti vyrobiv / O. A. Kuzin, Ya. M. Kusyi, V. H. Topilnytskyi // Technology Audit and Production Reserves. - Vol. 1, No.1(21). - 2015. - P.15-21. doi:10.15587/2312-8372.2015.37678.

5. Pronikov A. S. Nadezhnost' mashin / A. S. Pronikov. - M.: Mashinostroenie, 1978. - $592 \mathrm{p}$.

6. Xue L. Constitutive modeling of void shearing effect in ductile fracture of porous materials / L. Xue // Engineering Fracture Mechanics. - Volume 75 (11). - 2008. - P. 3343-3366.

7. Lian J. A hybrid approach for modelling of plasticity and failure behaviour of advanced high-strength steel sheets / J. Lian, M. Sharaf, F. Archie., S. Mu“nstermann // International Journal of Damage Mechanics. Volume 22 (2). - 2008. - P. 188-218. 


\section{«Системні технології» 5 (124) 2019 «System technologies»}

\section{Технологічне успадковування властивостей при забезпеченні параметрів якості ви- робу в процесі його виготовлення}

Проаналізовано недопустимі відмови виробів, що пов'язані із технологією їх виготовлення. Розроблено принципову схему формування параметрів якості деталей машин. Запропоновано математичний вираз для прогнозування імовірності невідбракування придатних до подальшої експлуатації виробів $P(t)$ із врахуванням технологічного успадковування. Розглянуто методи оцінювання пошкоджуваності заготовок виробів, отриманих обробкою тиском і литвом. Подальші дослідження стосуються оптимізації структури технологічних процесів виготовлення виробів із врахуванням технологічної спадковості при раціональному поєднанні заготівельних, чорнових, півчистових, чистових, фінішних і викінчувально-зміцнювальних операцій.

Technological inheritability of properties for providing of quality parameters of part during it manufacturing

One of the priority tasks of modern mechanical engineering industry is to improve the quality of parts and machines, to provide their operational condition and reliability parameters. The solution of this problem is achieved by controlling the manufacturing process of the parts and machines assembly with providing the specified technical requirements. Objectoriented technological processes with step-by-step execution of interconnected stages of parts manufacturing are not effective for modern mechanical engineering industry. The development of scientific and applied foundations of technological inheritability of quality parameters for providing the operational characteristics of parts in the design of functionally oriented technologies is relevant for the systematic maintenance of the Life Cycle of a Part. The prohibitive failures of parts, which related with their manufacturing process, have been analyzed. The aim of this research is to develop a principal scheme for the formation of quality parameters of part with predict of the probability of its failure in manufacturing, taking into account the technological inheritability of properties. The basic scheme forming of the quality parameters of machine parts is developed. The mathematical expression is proposed to predict the probability of non-rejection of the parts $P(t)$ suitabled for further exploitation, taking into account the technological inheritance. Methods for assessing the damageability of the blanks manufactured by pressure treatment and casting have been considered. The developed mathematical model makes it possible to predict the probability of invisible machine-building products $P(t)$, which are suitable for further use, taking into account the structure of the technological process and the technological inheritance of properties. Further research is related with optimization of technological processes structure of parts manufacturing taking into account technological inheritability with rational combination of blank operations, rough machining, semi-rough machining, finish machining, finishing and finishing-hardening operations.

Кусий Ярослав Маркіянович - докторант кафедри «Технологія машинобудування» Національного університету «Львівська політехніка».

Кусый Ярослав Маркиянович - докторант кафедры «Технология машиностроения» Национального университета «Львовская политехника».

Kusyi Yaroslav - Doctoral candidate of the Mechanical Engineering Department, Lviv Politechnic National University. 